12

\title{
Электрическая прочность диэлектриков при воздействии двуполярных импульсов напряжения субмикросекундной длительности
}

\author{
(C) В.Ф. Важов, Е.В. Петренко, А.С. Юдин
}

Инженерная школа новых производственных технологий, Томский политехнический университет, 634050 Томск, Россия

e-mail:evgenius293@mail.ru

Поступило в Редакцию 1 декабря 2021 г.

В окончательной редакции 28 декабря 2021 г.

Принято к публикации 28 декабря 2021 г.

\begin{abstract}
Впервые предложены и проведены исследования по определению пробивных напряжений различных диэлектрических сред (воздух, вода, горные породы) при одновременной подаче на электродную систему двух импульсов от двух генераторов напряжений разной полярности - положительной и отрицательной, что в два раза уменьшает рабочее импульсное напряжение каждого генератора. Эксперименты показали, что в этом случае для всех сред происходит снижение пробивного напряжения по сравнению с однополярным импульсом напряжения, которое достигает $28 \%$ - при пробое песчаника, $23 \%$ - гранита, $24 \%$ - воды, $25 \%$ - воздуха. Приведено физическое объяснение обнаруженному эффекту.
\end{abstract}

Ключевые слова: электрический пробой, двуполярный импульс напряжения, пробивное напряжение, канал разряда.

DOI: $10.21883 /$ JTF.2022.04.52253.304-21

\section{Введение}

Открытие, сделанное в области электрической прочности твердых и жидких диэлектриков в субмикрои микросекундном диапазоне воздействия импульсов высокого напряжения, позволило предложить новые способы разрушения твердых тел, в частности технологии электроимпульсного (ЭИ) бурения, резания, дробления и др. $[1,2]$.

Формирование канала пробоя и пробой являются основополагающими процессами для ЭИ технологий. При уменьшении времени воздействия импульсного напряжения прочность твердых и жидких диэлектриков возрастает с разной степенью. Это приводит к тому, что при воздействии импульсов напряжения с длительностью фронта менее $10^{-6} \mathrm{~s}$ электрическая прочность жидких диэлектриков становится выше прочности твердых диэлектриков и горных пород [1,2]. При расположении электродов на одной поверхности твердого непроводящего тела под слоем жидкости канал разряда развивается в твердом теле. Запасенная энергия в генераторе импульсных напряжений (ГИН) выделяется в канал разряда за время $10^{-6}-10^{-5} \mathrm{~s}$, вследствие чего происходит электровзрыв с отрывом части твердого материала, расположенного над каналом разряда [2]. ЭИ способ разрушения горных пород превосходит современные механические способы разрушения крепких горных пород как по эффективности, так и по производительности. Достоинства способа доказаны как при лабораторных исследованиях, так и в полевых условиях.
Наиболее полное обобщение научных данных по способу ЭИ дезинтеграции материалов, полученных преимущественно в СССР во второй половине $\mathrm{XX}$ века, можно найти в монографиях [2,3]. В настоящее время исследования в данной области ведутся в Германии [4], США [5], Австралии [6], Китае [7], России [8] и ряде других стран. Однако широкого промышленного применения ЭИ технологии не получили, кроме, может быть, в установках ЭИ дезинтеграции производства компании SelFrag [9].

Одной из причин, сдерживающих внедрение ЭИ способа в промышленность, является необходимость использования высокого напряжения (сотни $\mathrm{kV}$ ). Предложено несколько вариантов снижения импульсного рабочего напряжения, однако все они имеют различного рода ограничения $[2,10]$. Нами предлагается способ снижения импульсного рабочего напряжения при использовании двух ГИН, обеспечивающих одновременную подачу импульсов разной полярности на электродную систему напряжением для каждого ГИН в два раза меньшим, чем при однополярном генераторе. Подобное решение для ЭИ технологий предлагается впервые, и какие-либо эксперименты в этой области отсутствуют.

Целью настоящей работы является исследование возможности применения двуполярного импульса напряжения для ЭИ технологий как способа снижения рабочего напряжения отдельного генератора. Двукратное снижение рабочего напряжения способствует значительному увеличению срока службы компонентов генератора, а также изоляционных элементов и конструкций, переда- 


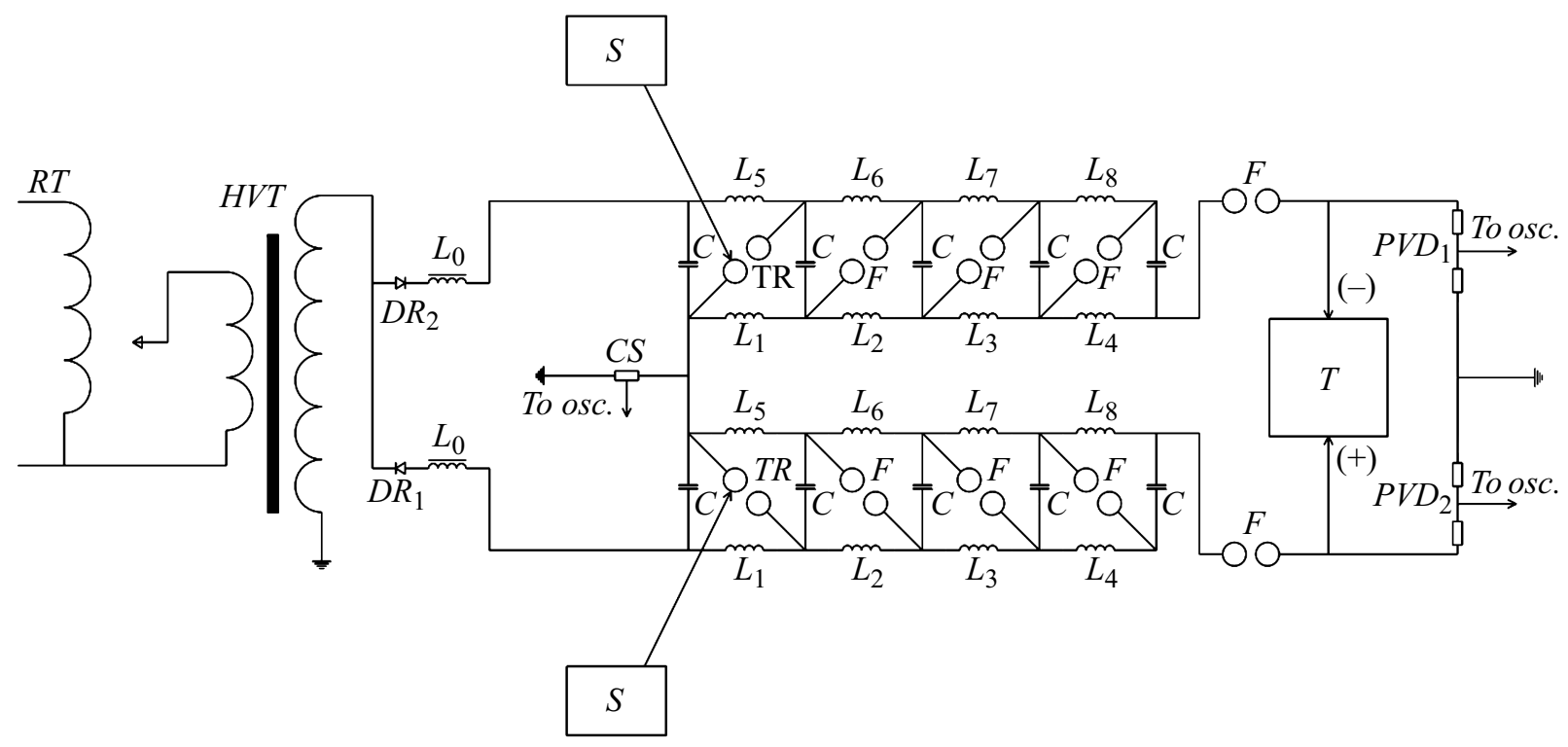

Рис. 1. Электрическая схема испытательной установки: $R T-$ регулировочный трансформатор, $H V T-$ высоковольтный трансформатор, $L_{0}$ - зарядные дроссели, $D R_{1}, D R_{2}-$ выпрямители, $C-$ емкость, $L_{1}-L_{8}-$ индуктивности, $T R-$ тригатрон, $F$ - искровой промежуток, $P V D_{1}, P V D_{2}$ - делители напряжения, $C S$ - токовый шунт, $T$ - разрядная камера, $S$ - запускающие генераторы.

ющих напряжение от ГИН к электродной системе, что чрезвычайно важно для надежной работы ЭИ установок.

\section{1. Методика}

На рис. 1 приведена общая электрическая схема испытательной установки, которая состоит из блоков:

- зарядного высоковольтного устройства с элементами измерения высокого выпрямленного напряжения, защитными устройствами и пультом управления;

- двух генераторов высоковольтных импульсных напряжений с устройствами управляемого запуска на базе тригатронов;

- блоков измерения высоких импульсных напряжений при помощи малоиндуктивных омических делителей напряжения, токового шунта для измерения тока при пробое;

- испытательной ячейки из полиэтилена, заполненной водой с системой электродов, куда помещаются испытуемые образцы горных пород.

Для реализации условий электроимпульсного пробоя и разрушения твердых тел требуется источник с необходимыми временными и энергетическими параметрами. В качестве такового широкое применение нашли емкостные генераторы импульсных высоких напряжений по схеме Аркадьева-Маркса, которые применены в наших исследованиях. Генераторы платформенного типа состоят из пяти ступеней. Каждая ступень снабжена конденсаторами типа ИК - 100/0.1, где $100-$ номинальное рабочее напряжение, $[\mathrm{kV}], 0.1$ - емкость, $[\mu \mathrm{F}]$. Рабочее напряжение ГИН регулируется при помощи изменения расстояния между шаровыми разрядниками на каждой ступени. Зарядное напряжение каждого ГИН не превышает $35 \mathrm{kV}$. Из опытов холостого хода и короткого замыкания генераторов следует, что длительность фронта импульсов составляет $\tau_{f}=0.2 \cdot 10^{-6} \mathrm{~s}$, а волновое сопротивление $Z_{w}=12.0 \Omega$.

При подключении нагрузки в виде электродной системы в воде параметры импульса изменяются: длительность фронта увеличивается до $\tau_{f}=0.24 \cdot 10^{-6} \mathrm{~s}$, а длительность импульса напряжения уменьшается вследствие большой емкости между электродами и малого удельного сопротивления воды.

Для синхронизации работы обоих генераторов применены схемы управления разрядниками тригатронного типа с регулируемым напряжением и временем срабатывания.

Блок измерения высокого напряжения состоял из двух малоиндуктивных омических делителей для одновременного измерения напряжений двух ГИН - положительной и отрицательной полярности. Ошибка измерения параметров импульса напряжения не более $3.1 \%$ [11]. Токовый шунт позволял измерять разрядные токи амплитудой не менее $20 \mathrm{kA}$.

Испытательная ячейка состояла из полиэтиленового бака объемом $500 \mathrm{dm}^{3}$, в котором была установлена съемная электродная система из двух стержневых электродов (рис. 2).

Два стержневых электрода диаметром $8 \mathrm{~mm}$ располагались под углом друг к другу так, чтобы их рабочие концы оказывались на одной поверхности образца горной породы. Концы электродов со стороны образца были загнуты навстречу друг другу под углом $30^{\circ}$ и обработаны так, чтобы плоскость торца электрода 
была параллельна плоскости поверхности образца, как показано на рис. 2. Прижим электродов к поверхности образца обеспечивался только за счет их собственного веса. Каждый электрод подключался к своему ГИН при помощи изолированного провода. Расстояние между электродами изменялось в соответствии с планом эксперимента. Полиэтиленовый бак заполнялся водопроводной водой с удельным сопротивлением в исходном состоянии $\rho=(3.6-4.2) \cdot 10^{3} \Omega \cdot \mathrm{cm}$, поскольку вода предпочтительна в ЭИ технологиях как рабочая жидкость. В процессе работы производился контроль удельного сопротивления воды. При уменьшении $\rho<10^{3} \Omega \cdot \mathrm{cm}$ объем воды в баке заменялся.

В качестве образцов выбраны песчаник (коэффициент крепости по шкале М.М. Протодьяконова $f=6$ ) и гранит $(f=14)$, как наиболее распространенные в природе горные породы $[12,13]$. Образцы размерами $150 \times 100 \times 50 \mathrm{~mm}$ вырезались из моноблоков гранита и песчаника. Также исследовались пробивные напряжения воды при времени воздействия $\tau=0.24 \cdot 10^{-6} \mathrm{~s} \mathrm{c}$ электродной системой, как для горных пород. Пробой воздуха осушествлялся в слабонеоднородном поле между шаровыми электродами диаметром $12.5 \mathrm{~cm}$, для которых существуют международные таблицы пробивных напряжений в зависимости от расстояния между шарами и полярности потенциального электрода. Известно, что при положительной полярности потенциального электрода пробивные напряжения несколько меньше, чем при отрицательной его полярности [11]. В данной работе сравнение пробивных напряжений при двуполярном воздействии осуществлялось с пробивными напряжениями, полученными для положительной полярности потенциального электрода. Шаровые электроды располагались горизонтально на опорных изоляторах. Каждый электрод

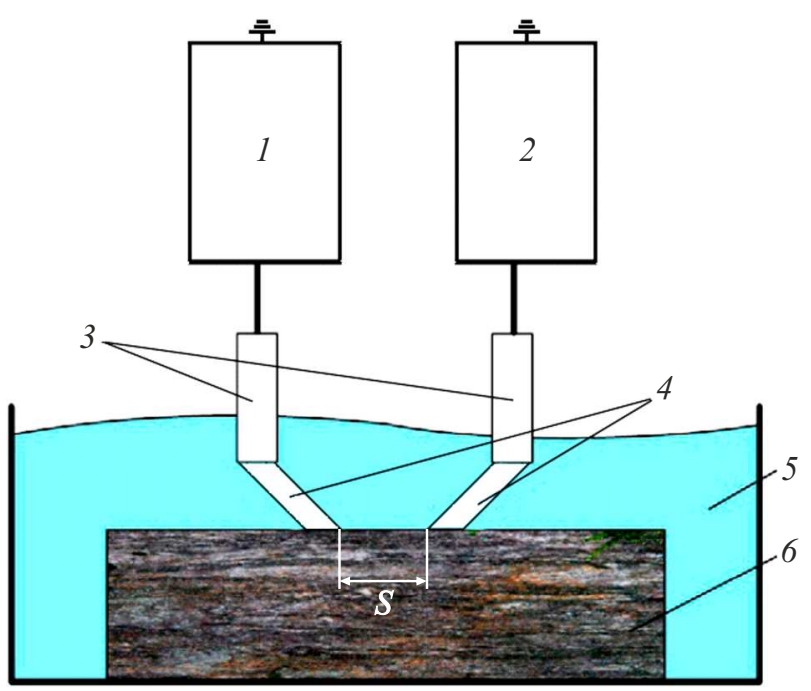

Рис. 2. Схема расположения электродной системы на образце: 1,2 - генераторы импульсного напряжения, 3 - изоляция, 4 - электроды, 5 - жидкость, 6 - горная порода, $S-$ расстояние между электродами.

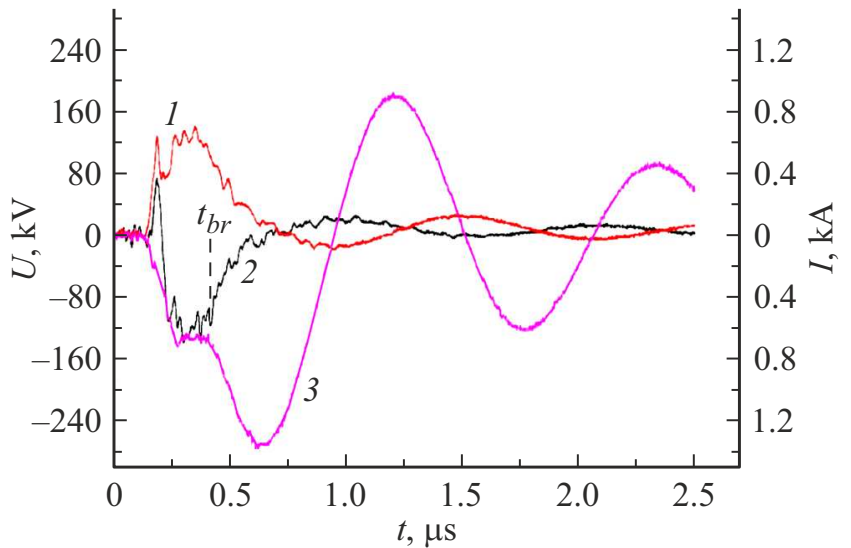

Рис. 3. Осциллограмма тока и напряжения: 1 - импульс напряжения положительной полярности, 2 - импульс напряжения отрицательной полярности, 3 - ток в контуре, $t_{b r}$ - время до пробоя.

был подключен к отдельному генератору. Количество пробоев, произведенных для заданных условий, было не менее: для воды и воздуха - 50, для горных пород 30. Дисперсия пробивных напряжений для горных пород не превышала $10 \%$.

Так как ЭИ эффект осуществляется при временах воздействия напряжения в субмикросекундом диапазоне, при сравнительных испытаниях непременным условием является определение пробивных напряжений при одинаковых или близких временах до пробоя. Это важно потому, что с уменьшением времени до пробоя пробивное напряжение для всех диэлектриков не является постоянным, оно возрастает, причем с различной скоростью [2].

В зависимости от электрической прочности диэлектрика и расстояния между электродами при заданной величине рабочего напряжения пробой может происходить на фронте, амплитуде и спаде импульса напряжения. В наших опытах во всех случаях, пробивное напряжение определялось по максимальной амплитуде импульса напряжения [10], а время до пробоя по осциллограмме тока (рис. 3).

\section{2. Физические аспекты пробоя твердых и жидких диэлектриков}

С точки зрения ЭИ технологий, исследователей главным образом интересуют процессы пробоя в зависимости от полярности воздействующего напряжения в твердых и жидких диэлектрических материалах, к которым относятся и горные породы.

В работах Ю.Н. Вершинина разработана современная новая теория пробоя твердых диэлектриков на импульсном напряжении $[14,15]$, которая положена в основу наших предположений. Воздействие электрического поля на диэлектрики вызывает протекание в них тока. При воздействии высокого напряжения, достаточного для 
пробоя, ток перед пробоем называется предпробивным. Предпробивной ток в (твердом) диэлектрике слагается из электронного и дырочного токов, протекающих в одном направлении - один в зоне проводимости, другой в валентной зоне. В процессе формирования разряда участвуют оба типа носителей заряда - и электроны, и дырки. Однако в одном случае их роль сводится лишь к изменению картины распределения потенциала и соответственно искривлению энергетических зон в разрядном промежутке, а в другом - эти носители заряда отвечают за пробой. Чтобы подчеркнуть их функциональное различие, первые называют неосновными, а вторые - основными носителями заряда. При положительной полярности электрода неосновными носителями будут дырки, а основными - электроны. При отрицательной полярности дырки будут основными, а электроны - неосновными носителями заряда [15].

При развитии разряда с анода ответственными за пробой носителями заряда являются электроны. Тогда скорость развития разряда

$$
V^{+}=V_{n}=\mu_{n} E(U) .
$$

При развитии разряда с катода ответственными за пробой являются дырки и скорость развития разряда

$$
V^{-}=V_{p}=\mu_{p} E(U)
$$

где $V_{n}, V_{p}$ - скорость диффузии электронов и дырок соответственно, $\mu_{n}, \mu_{p}$ - подвижность электронов и дырок.

Отсюда при $E=$ const, где $E-$ напряженность электрического поля на электродах,

$$
\frac{V^{+}}{V^{-}}=\frac{V_{n}}{V_{p}}=\frac{\mu_{n}}{\mu_{p}}
$$

Подвижность электронов в твердых диэлектриках выше, чем дырок. Следовательно, $V^{+}>V^{-}$.

На основании этого пробивное напряжение на положительной полярности импульса меньше, чем на отрицательной, т. е. $U^{+}<U^{-}$при $\mu_{n}>\mu_{p}$ [14].

Ионизация в канале пробоя структуры диэлектрика осуществляется электронами более интенсивно, чем дырками, что также способствует уменьшению пробивного напряжения при положительной полярности электрода и увеличению $V^{+}$.

Время формирования разряда в твердых диэлектриках является функцией подвижности основных носителей

$$
t_{p}=\frac{d}{\mu E_{b r}}
$$

где $d-$ толщина диэлектрика в месте пробоя, $E_{b r}-$ напряженность электрического поля при пробое. Из (1) следует, что время формирования разряда:

1) увеличивается с возрастанием $d$;

2) уменьшается с увеличением перенапряжения;
3) при положительной полярности меньше, чем при отрицательной полярности электрода, так как $\mu_{n}>\mu_{p}[14]$.

Это объяснение необходимо дополнить еще двумя факторами, влияющими на эффект полярности:

1) вероятность образования первичных электронов Pn больше вероятности образования первичных дырок $P_{p}$, т. е. $P_{n}>P_{p}$;

2) коэффициент ударной ионизации электронами $\alpha$ больше коэффициента ударной ионизации дырками $\beta$, т. е. $\alpha=3 \beta[14]$.

Оба эти фактора $p_{n}>p_{p}$ и $\alpha>\beta$ приводят к тому, что $E_{b r}^{+}<E_{b r}^{-}$[14].

Возникновение первичного канала разряда как с катода, так и с анода имеет одинаковую тепловую физическую природу. Различие состоит в том, что при разряде с катода в его формировании участвуют преимущественно не собственные электроны, а инжектированные из катода, при разряде с анода - собственные электроны из нижних донорных уровней диэлектрика.

При положительной полярности потенциального электрода в резконеоднородном поле разряд начинает развиваться с потенциального электрода при минимальном напряжении пробоя и заканчивается еще до появления разрядов у заземленного (отрицательного) электрода. Напряжение и время пробоя минимальны. Для отрицательной полярности потенциального электрода характерна задержка начала развития разряда и уровень напряжения пробоя заметно выше, чем при положительной полярности [2].

Одновременное приложение напряжений обеих полярностей к электродной системе вызывает увеличение напряженности электрического поля на электроде, который был бы заземлен, ввиду отсутствия действия „земли“ [2]. Этот эффект способствует уменьшению пробивного напряжения между электродами. Кроме этого, развитие двух встречных каналов разряда с обоих электродов, хотя и с некоторой задержкой во времени и меньшей скоростью развития с отрицательного электрода, будет увеличивать напряженность между каналами в процессе их развития и способствовать более быстрому во времени и при меньшем напряжении пробою всего межэлектродного промежутка. На основании вышеизложенного для двух стержневых потенциальных электродов (резконеоднородное поле) следует ожидать уменьшения пробивного напряжения по сравнению с системой, когда один электрод заземлен.

Поскольку в системе двух симметричных потенциальных электродов одинаковой формы и размеров эффект полярности отсутствует, сравнение пробивных напряжений проводится для однополярных промежутков с положительной полярностью потенциального электрода и заземленного электрода. 
Характеристики пробоя разных сред при воздействии двуполярного импульса напряжения

\begin{tabular}{|c|c|c|c|c|c|c|}
\hline Материал & $S, \mathrm{~mm}$ & $U_{b r \Sigma}, \mathrm{kV}$ & $t_{b r}, \mu \mathrm{s}$ & $U_{b r}, \mathrm{kV}$ & $U_{b r} / U_{b r \Sigma}$ & Дисперсия, \% \\
\hline Песчаник & $\begin{array}{l}20 \\
30\end{array}$ & $\begin{array}{l}206 \\
205\end{array}$ & $\begin{array}{l}0.19 \\
0.31\end{array}$ & $\begin{array}{l}234[16] \\
263[16]\end{array}$ & $\begin{array}{l}1.18 \\
1.28\end{array}$ & \multirow[b]{2}{*}{$10-20[3]$} \\
\hline Гранит & $\begin{array}{l}20 \\
30 \\
50\end{array}$ & $\begin{array}{l}248 \\
290 \\
320\end{array}$ & $\begin{array}{c}0.24 \\
0.39 \\
1.8\end{array}$ & $\begin{array}{l}306[16] \\
316[17] \\
362[17]\end{array}$ & $\begin{array}{c}1.23 \\
1.1 \\
1.14\end{array}$ & \\
\hline Вода & 15 & 290 & 0.38 & $360[15]$ & 1.24 & $8[3]$ \\
\hline Воздух & $\begin{array}{l}64 \\
75 \\
97\end{array}$ & $\begin{array}{l}172 \\
219 \\
236\end{array}$ & $\begin{array}{l}0.15 \\
0.18 \\
0.19\end{array}$ & $\begin{array}{l}216[11] \\
244[18] \\
270[18]\end{array}$ & $\begin{array}{l}1.25 \\
1.12 \\
1.14\end{array}$ & $3-3.16[19,20]$ \\
\hline
\end{tabular}

Примечание. $S$ - расстояние между электродами, $U_{b r \Sigma}$ - суммарное напряжение пробоя на электродах положительной и отрицательной полярности, $t_{b r}$ - длительность времени до пробоя, $U_{b r}$ - пробивное напряжение при однополярном положительном электроде из литературных источников для условий, соответствующих нашим экспериментам, $U_{b r} / U_{b r \Sigma}$ - относительная величина снижения пробивных напряжений при однополярном $U_{b r}$ и двуполярном $U_{b r \Sigma}-$ импульсе напряжения.

\section{3. Экспериментальные результаты}

Исследования проводились для трех принципиально различных сред - газообразная, жидкая и твердая - с целью обнаружения предполагаемого эффекта снижения пробивного напряжения для всех сред. Тем более, что ЭИ эффект осуществляется в комбинированной среде: твердое тело-жидкость. В таблице приведены обобщенные результаты всех экспериментов.

\section{1. Песчаник}

Горная порода осадочного типа, физико-механические характеристики которой изменяются в очень широком диапазоне [12,13]. Исследуемая нами порода обладает относительно низким пробивным напряжением $U_{b r \Sigma}$ (см. таблицу). Увеличение расстояния между электродами в 1.5 раза практически не изменило $U_{b r \Sigma}$, что в первую очередь определяется временем до пробоя: при $S=20$ mm пробой произошел практически на амплитуде импульса напряжения, а при $30 \mathrm{~mm}$ - на спаде, что хорошо согласуется с изменением вольт-секундной характеристики. Величина пробивного импульсного напряжения при пробое на спаде определяется по амплитуде. В литературе для близких условий испытаний с однополярным ГИН и практически близких характеристиках песчаника даны значения пробивных напряжений для $S=20 \mathrm{~mm} ; U_{b r}=234 \mathrm{kV}$ и для $S=30 \mathrm{~mm} ; U_{b r}=263 \mathrm{kV}$. В таблице показано, что по сравнению с литературными данными снижение $U_{b r \Sigma}$ достигает $28 \%$ [16].

Следует отметить, что при ЭИ эффекте канал разряда в твердом теле, особенно в горных породах, имеет стохастическую и вероятностную природу и его глубина внедрения и длина изменяются от разряда к разряду в широких пределах, что сказывается и на величине пробивного напряжения [17]. Тем не менее можно констатировать, что для песчаника при обоих потенциальных электродах пробивное напряжение меньше, чем при одном потенциальном, а другом заземленном электродах, с учетом указанной выше дисперсии.

\section{2. Гранит}

Магматическая горная порода, физико-механические свойства которой изменяются в широких пределах, например, коэффициент крепости по М.М. Протодьяконову изменяется в диапазоне 6-19 [12]. Электрическая прочность горных пород коррелирует с коэффициентом крепости [16]. Как указано выше, коэффициент крепости исследуемых образцов гранита составляет 14, т. е. достаточно крепкий гранит. Он обладает более высокой, чем песчаник, электрической прочностью, поэтому необходимо соответствующим образом настраивать генератор импульсных напряжений, особенно при увеличении расстояний между электродами.

Из таблицы видно, что пробивное напряжение при однополярном импульсе $U_{b r}$ выше [16,17], чем при двуполярном. Необходимо отметить, что результаты сравнения для однополярного импульса взяты из разных источников: для $S=20 \mathrm{~mm}$ - эксперимент [16], для $S=30,50 \mathrm{~mm}$ - расчетная формула [17]. Здесь также наблюдается снижение суммарного пробивного напряжения при воздействии на образцы гранита двуполярного импульса напряжения, которое достигает 23\% несмотря на то, что пробой происходил как на фронте, так и на спаде импульса напряжения, что превышает дисперсию пробоя разных горных пород (см. таблицу) [3].

\section{3. Вода}

В субмикросекундном временном диапазоне воздействия импульсного напряжения электрическая прочность воды существенно превышает электрическую прочность горных пород и приближается к прочности трансформаторного масла [2], поэтому расстояние между электродами изменено до $S=15 \mathrm{~mm}$. И даже в этом 
случае пробой происходит на спаде импульса напряжения, как у гранита при $S=30$ и $50 \mathrm{~mm}$ (см. таблицу).

В работе [21] проведены исследования электрической прочности воды в широком диапазоне изменения расстояний $S=10-90 \mathrm{~mm}$. На основании этих результатов в таблице приведено значение $U_{b r}$ для однополярного положительного импульса.

Сравнение полученных результатов показывает, что воздействие двуполярного импульса вызывает снижение пробивного напряжения до $24 \%$, что существенно больше, чем дисперсия пробивных напряжений воды (см. таблицу) [3]. Следовательно, эффект снижения пробивного напряжения при воздействии двуполярного импульса сохраняется в жидкой среде.

\section{4. Воздух}

Пробой воздуха осуществлялся в квазиоднородном поле шар-шар с переходом в слабонеоднородное при увеличении расстояния более $64 \mathrm{~mm}$. Значения пробивных напряжений для шаровых разрядников различных диаметров и расстояний между шарами приведены в таблицах международной электротехнической комиссии [11]. Однако их использование ограничивается параметрами импульса напряжения - 1.2/50 $\mathrm{s}$, так как импульсы меньшей длительности требуют поправки, поскольку возрастает пробивное напряжение. Данная поправка учитывается „коэффициентом импульса $(\beta)^{6,}$, который с уменьшением времени воздействия напряжения до $10^{-8} \mathrm{~s}$ и менее может достигать $(\beta) \geq 2.2[18,22]$. С учетом нарушения однородности электрического поля при увеличении расстояния между электродами больше 0.5 диаметра шаров, коэффициент $(\beta)$ возрастает [22]. Для наших условий эксперимента $(\beta)=1.4$ [3]. В таблице показано, что при воздействии двуполярного импульса напряжение пробоя уменьшается до 1.25 раза относительно однополярного импульса напряжения, что значительно превышает дисперсию пробивных напряжений воздуха (см. таблицу) [19,20].

\section{Заключение}

Представленные результаты исследований позволяют констатировать, что для условий осуществления ЭИ эффекта приложение к двухэлектродной системе двуполярного импульса напряжения вызывает снижение пробивного напряжения относительно пробоя однополярным импульсом для всех исследованных сред твердое тело, жидкость, газ.

При положительной полярности потенциального электрода в случае однополярного импульса разряд с заземленного электрода не успевает зажечься и начать развиваться за время действия импульса вследствие относительно низкого потенциала на заземленном электроде и экранирующего действия „земли“, т. е. за счет влияния „земли“ на заземленном электроде напряженность электрического поля понижена. Это препятствует зажиганию и развитию канала разряда с него [14].

При двух потенциальных электродах разной полярности (отсутствует „земля“) при одинаковой величине потенциала на каждом электроде напряженность электрического поля будет определяться только геометрическими параметрами и формой электродов.

Для симметричных и одинаковых по конфигурации и размерам электродов напряженность на каждом из них будет одинакова. В этом случае зажигание канала разряда на каждом из них будет определяться механизмом зажигания, который зависит от полярности электрода. На электроде с отрицательной полярностью напряжения зажигание канала разряда происходит с некоторой задержкой и меньшей скоростью его развития по сравнению с процессами на электроде положительной полярности. Разряд в твердом теле у положительного электрода зажигается при меньшем напряжении, чем у отрицательного электрода и скорость его продвижения существенно выше $\left(V_{a}=(14.1-26.7) \cdot 10^{6} \mathrm{~cm} / \mathrm{s}-\right.$ скорость развития канала разряда с анода, $V_{c}=(0.26-7.2) \cdot 10^{6} \mathrm{~cm} / \mathrm{s}-$ скорость развития канала разряда с катода $[2,15])$. Главным фактором, определяющим скорость продвижения канала разряда, является напряженность электрического поля на кончиках каналов разрядов, которая, в свою очередь, определяется приложенным к электродам напряжением и расстоянием между встречно развивающимися каналами с электродов положительной и отрицательной полярности. Это существенно увеличивает напряженность в промежутке между кончиками (головками) каналов, увеличивает скорость их продвижения между электродами и, как следствие, уменьшает пробивное напряжение. Следовательно, пробивное напряжение при двуполярном импульсе не может быть больше, чем пробивное напряжение при положительном однополярном импульсе.

Исследования, проведенные в настоящей работе, показали, что эффект снижения пробивного напряжения при воздействии двуполярного импульса напряжения характерен для всех диэлектрических сред-газ, жидкость, твердое тело. Реализация этого эффекта для ЭИ технологии позволит существенно, более чем в два раза, снизить рабочие напряжения как генераторов импульсов, так и высоковольтных передающих изоляционных систем от генераторов к нагрузке - рабочим электродным системам, которые, например при бурении, могут быть удалены на сотни и тысячи метров друг от друга.

\section{Финансирование работы}

Работа выполнена при поддержке проекта РФФИ, грант № 19-38-90071. 


\section{Конфликт интересов}

Авторы заявляют, что у них нет конфликта интересов.

\section{Список литературы}

[1] А.А. Воробьев, Г.А. Воробьев, А.Т. Чепиков. Закономерности пробоя твердого диэлектрика на границе раздела с жидким диэлектриком при действии импульса напряжения (свидетельство на открытие № А-122 от 29.04.1998 с приоритетом от 14.12.1961)

[2] Б.В. Семкин, А.Ф. Усов, В.И. Курец. Основы электроимпульсного разрушения материалов (Наука, СПб., 1995), c. 276.

[3] В.И. Курец, А.Ф. Усов, В.А. Цукерман. Электроимпульсная дезинтеграция материалов (Апатиты, Кольского НЦ РАН, 2002), c. 234.

[4] E. Anders, M. Voigt, F. Lehmann. Electric Impulse Drilling: the future of drilling technology begins now. ASME. International Conference on Offshore Mechanics and Arctic Engineering, Polar and Arctic Sciences and Technology; Petroleum Technology. 2017. 8:V008T11A024.

DOI: 10.1115/OMAE2017-61105

[5] J.A. Gilbrech. Pulse Transformer for Downhole Electrocrushing Drilling. Patent WO2018186828; 2018.

[6] W. Zuo, F. Shi, E. Manlapig. Minerals Engineering, 79, 306 (2015). DOI: 10.1016/j.mineng.2015.03.022

[7] Ch. Li, L. Duan, J. Kang, Ao Li, Y. Xiao, V. Chikhotkin. J. Petroleum Sci. Engineer., 205, 108807 (2021). DOI: $10.1016 /$ j.petrol.2021.108807

[8] D. Molchanov, V. Vazhov, I. Lavrinovich, V. Lavrinovich, N. Ratakhin. Downhole Generator Based on a Line Pulse Transformer for Electro Pulse Drilling. 21st International Conference on Pulsed Power (PPC) (IEEE). DOI: 10.1109/PPC.2017.8291167

[9] Электронный ресурс. Режим доступа: http://www.selfrag.com

[10] Ю.И. Кузнецов, В.Ф. Важов, М.Ю. Журков. Известия вузов. Физика, 4, 17 (2011).

[11] Ю.В. Корицкий, В.В. Пасынков, Б.М. Тареев. Справочник по электротехническим материалам (Энергия, М., 1974), т. 1, с. 583.

[12] В.С. Зинченко, Г.Г. Номоконова, Л.Я. Ерофеев, Г.С. Вахромеев. Физика горных пород (НТЛ, Томск, 2006), с. 520.

[13] Н.И. Куличихин, Б.И. Воздвиженский. Разведочное бурение (Недра, М, 1973), с. 440.

[14] Ю.Н. Вершинин. Электронно-тепловые и детонационные прочессы при электрическом пробое твердых диэлектриков (УрО РАН, Екатеринбург, 2000), с. 258.

[15] Ю.Н. Вершинин. Электрический пробой твердых диэлектриков (Наука, Новосибирск, 1968), с. 211.

[16] В.С. Малахов. Исследование импульсной электрической прочности горных пород применительно к их разрушению электроимпульсным способом дисс. к.т.н. (Томск, 1968)

[17] V.Ya. Ushakov, V.F. Vazhov, N.T. Zinoviev. Electrodischarge Technology for Drilling Wells and Concrete Distruction (Springer Nature Switzerland A.G., 2019), p. 261.
[18] А.П. Александров, А.Ф. Вальтер, Б.М. Вул, С.С. Гутин, И.М. Гольдман, Л.И. Закгейм, Е.В. Кувшинский. Под ред. А.Ф. Вальтера. Физика диэлектриков (ГТТИ, М.-Л., 1932), c. 560.

[19] Д.В. Разевиг, Л.Ф. Дмоховская, В.П. Ларионов. Техника высоких напряжсений, под ред. проф. Д.В. Разевига (Энергия, М.-Л., 1964), с. 472.

[20] Г.Н. Александров, Е.М. Рудаков. Исследование влияния параметров атмосферного воздуха на разрядные напряжения длинных воздушных промежутков. Пробой диэлектриков и полупроводников (Энергия, М., 1964), c. 44-49.

[21] В.Ф. Важов, Н.В. Козлова. Электричество, 6, 73 (2012).

[22] Э.М. Базелян, И.М. Ражанский. Искровой разряд в воздуxe (Наука, Новосибирск, 1988), с. 103. 